\title{
Modus vivendi: invasive host/parasite relations-Charybdis longicollis Leene, 1938 (Brachyura: Portunidae) and Heterosaccus dollfusi Boschma, 1960 (Rhizocephala: Sacculinidae)
}

\author{
Gianna Innocenti · Bella S. Galil
}

(C) Springer Science+Business Media B.V. 2007

\begin{abstract}
Parasitic castrators, specifically rhizocephalan barnacles, considered as important regulators of host population density, were proposed as control agents for invasive decapod crustaceans. The temporal variability of the invasive parasitic barnacle Heterosaccus dollfusi prevalence was examined a decade after its introduction into the Mediterranean, with the purpose of elucidating whether it is indeed an efficient control agent of its invasive host, the swimming crab, Charybdis longicollis. Despite the high prevalence of the parasite and its injurious impact on the host reproduction, the Erythrean invasive host-parasite pair reached a modus vivendi with no noticeable reduction in the host population, and high rates of infestation and multiple infestation. It is suggested that high fecundity, "size refuge" formed by parasite-free larger males, and "open" recruitment dynamics, keep the popula-
\end{abstract}

Guest editors: Elizabeth J. Cook and Paul F. Clark Invasive Crustacea

\section{G. Innocenti}

Museo di Storia Naturale, Sezione Zoologica "La Specola", Università degli Studi di Firenze, via Romana 17, Firenze 50125, Italy

B. S. Galil $(\square)$

National Institute of Oceanography, Israel

Oceanographic and Limnological Research, POB

8030, Haifa 31080, Israel

e-mail: bella@ocean.org.il tion density of $C$. longicollis high enough to allow $H$. dollfusi, with its "closed" recruitment dynamics, to maintain its pandemic infection rates.

Keywords Charybdis $\cdot$ Heterosaccus $\cdot$ Invasive species · Host/parasite interaction · Erythrean invasion · Eastern Mediterranean

\section{Introduction}

The defining feature of the eastern Mediterranean biota has been the mass establishment of Red Sea species that entered through the Suez Canal (Galil, 2000). The unabated influx of the Erythrean (originating in the Red Sea) biota is rooted in the unceasing enlargement of the Canal that has altered its hydrography and hydrology, and enhanced its potential as a "corridor", allowing greater numbers of organisms through. Complex anthropogenic changes to the Levantine marine environment have made it more susceptible to invasion by modifying its hydrological properties, species diversity, and community structure (Galil, 2004). Absence of natural enemies, be it competitors, predators, pathogens, or parasites, is one of the oft-repeated explanations given for the success of alien biota (Wolfe, 2002; Torchin et al., 2003). Diminished parasitization of alien species may be attributed to reduced probability of 
infestation due to the small numbers of the founding population, its being composed of uninfected larval stages, or, in the case of parasites requiring more than one host during their life cycle, the absence of intermediate hosts in the new locale, and on the other hand, the host-specificity of some native parasites forestalling infection of alien hosts.

The swimming crab, Charybdis longicollis Leene, 1938 found in the Red Sea, the Persian Gulf and Madagascar, was first recorded in the Mediterranean in 1954 (Lewinsohn \& Holthuis, 1964) (Fig. 1). Soon after, its populations underwent an exponential growth stage: "The species became so abundant in southern Israel coastal waters that it now must be considered a true pest, the fishermen complain that their nets are filled with these crabs" (Lewinsohn \& Holthuis, 1964: p. 58). It occurs all along the Levant, from Egypt to Rhodes, and is common on sandy-mud bottoms at 25-60 m and occasionally deeper, where it may form as much as $70 \%$ of the benthic biomass (Galil, 1986; Ozcan et al., 2005). Release from parasites may have contributed to its success - of the thousands of specimens collected off the Israeli coast in over three decades, none were parasitized until 1992, when a few specimens were discovered carrying the externae of the parasitic barnacle Heterosaccus dollfusi Boschma, 1960 itself an Erythrean alien (Galil \& Lützen, 1995). Subsequent collections confirmed its presence on the easternmost part of the Anatolian coast (Oksnebjerg et al., 1997; B. Yokes, pers. comm.) (Fig. 2).

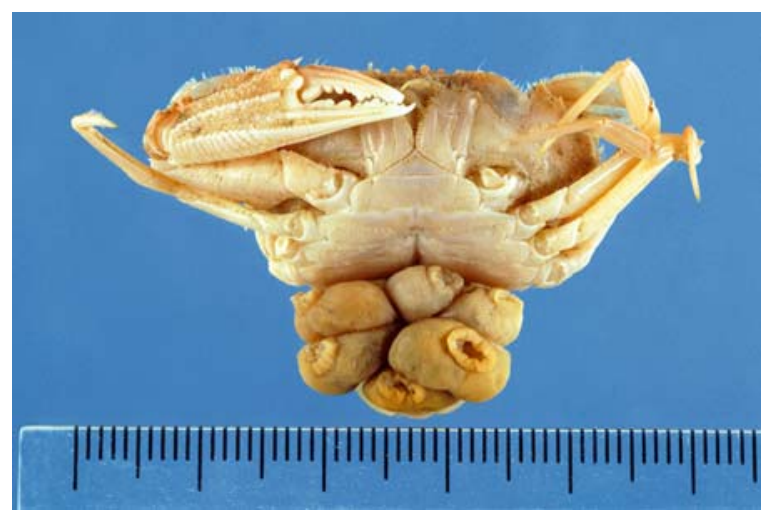

Fig. 1 Charybdis longicollis infected with Heterosaccus dollfusi
Heterosaccus dollfusi penetrates the young C. longicollis and forms a vegetative interna consisting of numerous microscopic roots. The late stage of the interna forms the reproductive part of the parasite (externa) that breaks through the host's skin assuming a sacciform shape and occupying the position normally taken by the eggs in berried females (Høeg \& Lützen, 1995). Infection causes degeneration of the gonads in both sexes, in effect sterilizing the hosts. It also modifies morphological traits: female hosts lose the swimmerets; male hosts lose the copulatory appendages, and their abdomen broadens to afford the parasite's externa optimal protection. The presence of the externa induces the host to simulate egg-grooming behaviour, even in male crabs, in which grooming and fanning the abdomen do not occur normally (Innocenti et al., 1998). The presence of the parasite modifies digging behaviour and inhibits burying in the sand, a common activity in non-infected crabs, and reduces belligerence in male crabs (Innocenti et al., 2003).

It has been suggested that biocontrol, involving the introduction of a predator, parasite or pathogen, may present an option for marine pests management, in particular invasive species (Thresher et al., 2000). Kuris (1997) suggested the use of endoparasitic rhizocephalan castrators, provided they are specific to the target host and effectively regulate its population density. The Erythrean invasion presented us with an interesting "field experiment": $H$. dollfusi had not been detected so far in any other portunid crab species inhabiting the Levantine sublittoral, alien or native, including the congeneric $C$. hellerii (A. Milne Edwards, 1867), but is it an efficient control agent? At a previously studied site, the prevalence of infection and occurrence of multiple externae over the past three years was measured and compared with earlier studies in order to estimate the dynamics of host-parasite populations in the second decade of its presence in the Levantine Sea.

\section{Methods}

The coast of Israel, at the southeastern corner of the Mediterranean, describes a nearly smooth 


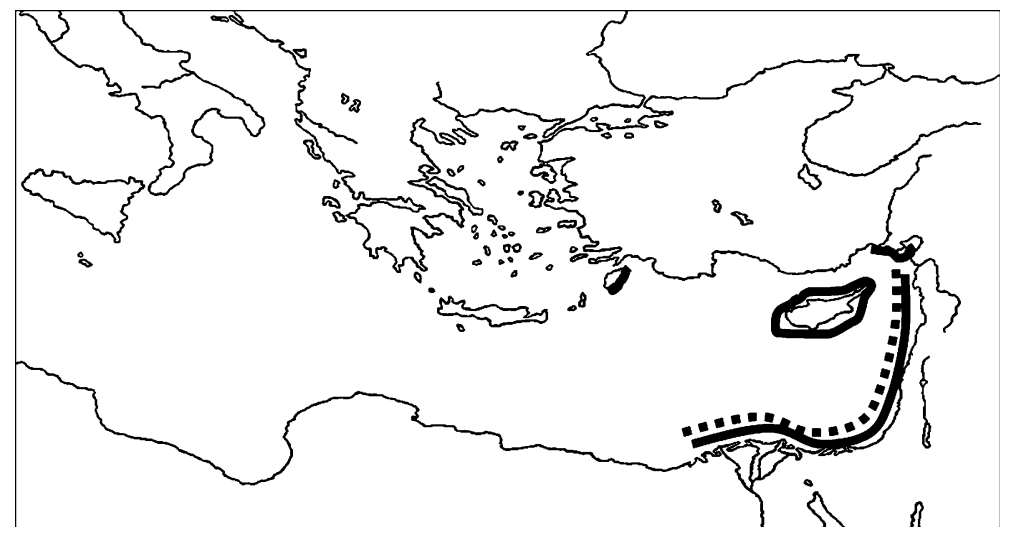

Fig. 2 Geographical distribution of Charybdis longicollis (continuous line) and Heterosaccus dollfusi (broken line)

curving arc, with a broad continental shelf. The macrobenthos was sampled within the framework of a monitoring program in the vicinity of the marine outfall of a sewage treatment plant at Palmahim, south of Tel Aviv. The material was collected by the R/V Shikmona using a $1.15 \mathrm{~m}$ wide beam trawl, at depth of $30-37 \mathrm{~m}$, in May 2002, 2004, and 2005. Each sample consisted of 12 trawls of identical duration (20 min), taken within a limited area. The material from all trawls was pooled. Carapace width $(\mathrm{CW}$-distance between tips of lateral spines to nearest $\mathrm{mm}$ ), sex, presence of parasite, and number of externae were noted. The data were compared applying the G-test and analyzed with the ANOVA. The SNK test was used as a post-hoc multicomparison test within the ANOVA, the level of significance was set at $P<0.05$.

\section{Results}

Prevalence of infestation

During May 2002, 2004, and 2005, 1742 specimens of C. longicollis were collected. Among these, 1049 were either externae-bearing, or infected morphologically-modified crabs. The prevalence of infection varied among the samples, $58.6 \%$ in 2002 , to $44.4 \%$ in 2004 , and $65.9 \%$ in 2005 (Table 1, 2).

The overall sex ratio was stable, with 62.6, 62.7, $62.5 \%$ males in 2002, 2004, and 2005 respectively, though among infected crabs the percentage of males was higher, 66.3, 71, 68.9\% respectively. The increasing prevalence of infestation was concurrent with a rise in the percentage of infected males in the samples, from $38.8 \%$ in

Table 1 Incidence of infection in Charybdis longicollis collected in Palmahim, May 2002, 2004, 2005

\begin{tabular}{|c|c|c|c|c|c|c|}
\hline & \multicolumn{2}{|c|}{ May 2002} & \multicolumn{2}{|c|}{ May 2004} & \multicolumn{2}{|c|}{ May 2005} \\
\hline & Total & $\%$ & Total & $\%$ & Total & $\%$ \\
\hline \multicolumn{7}{|l|}{ Uninfected } \\
\hline Male & 164 & 23.8 & 70 & 31.1 & 141 & 17.0 \\
\hline Female & 38 & 5.5 & 20 & 8.9 & 52 & 6.3 \\
\hline Ovigerous & 84 & 12.2 & 35 & 15.6 & 89 & 10.8 \\
\hline Total & 286 & & 125 & & 282 & \\
\hline \multicolumn{7}{|c|}{ Parasitized (externae-bearing) } \\
\hline Male & 268 & 38.8 & 71 & 31.6 & 376 & 45.5 \\
\hline Female & 136 & 19.7 & 29 & 12.9 & 169 & 20.4 \\
\hline Total & 404 & & 100 & & 545 & \\
\hline Parasite Ratio & 58.6 & & 44.4 & & 65.9 & \\
\hline
\end{tabular}

Parasite Ratio $=$ Parasite $/$ Total $(\mathrm{G}-$ Test $=39.250, \mathrm{df}=6, P<0.001)$

Incidence of uninfected and parasitized crabs among years $(\mathrm{G}-\mathrm{Test}=34.846, \mathrm{df}=2, P<0.001$ ) 
Table 2 Multiple comparison of the categories sex, year and state of infection (uninfected and parasitized crabs)

\begin{tabular}{llrrl}
\hline Source & df & SS & F Ratio & $P$ \\
\hline Sex & 1 & 4167.36 & 120.888 & $<0.0001$ \\
Year & 2 & 2283.75 & 33.124 & $<0.0001$ \\
State of infection & 1 & 1984.61 & 57.570 & $<0.0001$ \\
Sex vs. year & 2 & 811.72 & 11.773 & $<0.0001$ \\
Sex vs. state of infection & 1 & 2628.42 & 76.246 & $<0.0001$ \\
Year vs. state of infection & 2 & 199.62 & 2.895 & $\mathrm{~ns}$ \\
\hline
\end{tabular}

May 2002, 31.6\% in May 2004, and 45.5\% in May 2005.

\section{Effects of infestation on host size}

Examination of CW measurements of uninfected C. longicollis indicated that males were significantly larger than females, but whereas both the average and maximal size of uninfected males declined from 2002 to 2005 , the size of uninfected females did not differ significantly (ANOVA test: $F=47.6357$, df $=1732, \quad P<0.0001)$. Post hoc SNK test revealed that the uninfected males were always significantly larger than infected males and females, moreover, the infected males, although significantly smaller than uninfected males, were significantly larger than females, while there was no difference between infected and uninfected females (Table 3).

Examination of the size $(\mathrm{CW})$ frequency distribution of C. longicollis in May 2002, 2004, 2005 indicated that the largest number of crabs were between $35-45 \mathrm{~mm}$ wide, and that many in this size range were infected (Fig. 3). Larger male crabs $(\mathrm{CW}>55 \mathrm{~mm})$ were free of infestation.
Multiple infestation

Multiple infestation was common in C. longicollis, in May 2002, 2004, and 2005, with 47.6\%, 37.1\%, and $58.1 \%$ respectively of externa bearing hosts bearing more than one externa (comparison among the 3 years: $G=100.648, \quad \mathrm{df}=10$, $P<0.001 ; 2002$ vs. 2005 prevalence of multiple infestation: $G=52.907, \mathrm{df}=5, P<0.001$ ) (Table 4). Of special note was the number of crabs bearing 4-6 externae in the 2005 sample.

\section{Discussion}

Kuris $(1974,1997)$ suggested parasitic castrators, specifically rhizocephalan barnacles, may be important regulators of host population density, since they inflict reproductive death on their hosts, and proposed their use as control agents for invasive marine decapod crustaceans. Few studies, however, have documented the population dynamics of rhizocephalan barnacles and their hosts; fewer still described the population dynamics of alien rhizocephalan barnacles and their hosts in the region of their introduction (but see Hines et al., 1997; Galil \& Innocenti, 1999). The temporal variability of $H$. dollfusi prevalence was examined at a site within its introduced region, with the purpose of elucidating whether it is indeed an efficient control agent of its invasive decapod host, C. longicollis.

Charybdis longicollis entered the Mediterranean over half a century ago, but individuals harbouring the rhizocephalan barnacle were collected long after the host crab Mediterranean populations increased in density, affording the

Table 3 Carapace width in uninfected and parasitized Charybdis longicollis collected in Palmahim, May 2002, 2004, 2005

\begin{tabular}{|c|c|c|c|c|c|c|c|c|c|c|c|c|}
\hline & \multicolumn{4}{|c|}{ May 2002} & \multicolumn{4}{|c|}{ May 2004} & \multicolumn{4}{|c|}{ May 2005} \\
\hline & Mean & SD & $n$ & Range & Mean & SD & $n$ & Range & Mean & SD & $n$ & Range \\
\hline \multicolumn{13}{|l|}{ Uninfected } \\
\hline Male & 44.10 & 7.8 & 164 & $29.25-62.34$ & 41.40 & 9.7 & 70 & $21.08-57.18$ & 39.64 & 8.6 & 141 & $20.81-59.56$ \\
\hline Female + ovig. & 34.90 & 3.9 & 122 & $24.62-45.42$ & 34.32 & 4.4 & 55 & $21.11-42.34$ & 35.57 & 4.5 & 141 & $25.66-44.33$ \\
\hline \multicolumn{13}{|c|}{ Parasitized (externae-bearing) } \\
\hline Male & 39.12 & 5.4 & 268 & $25.27-54.78$ & 33.59 & 6.7 & 71 & $21.58-46-34$ & 35.59 & 4.8 & 376 & $23.30-51.97$ \\
\hline Female & 36.81 & 4.7 & 136 & $26.22-49.89$ & 34.67 & 6.2 & 29 & $22.40-47.03$ & 34.72 & 4.5 & 169 & $20.99-45.70$ \\
\hline
\end{tabular}

ovig. = ovigerous 

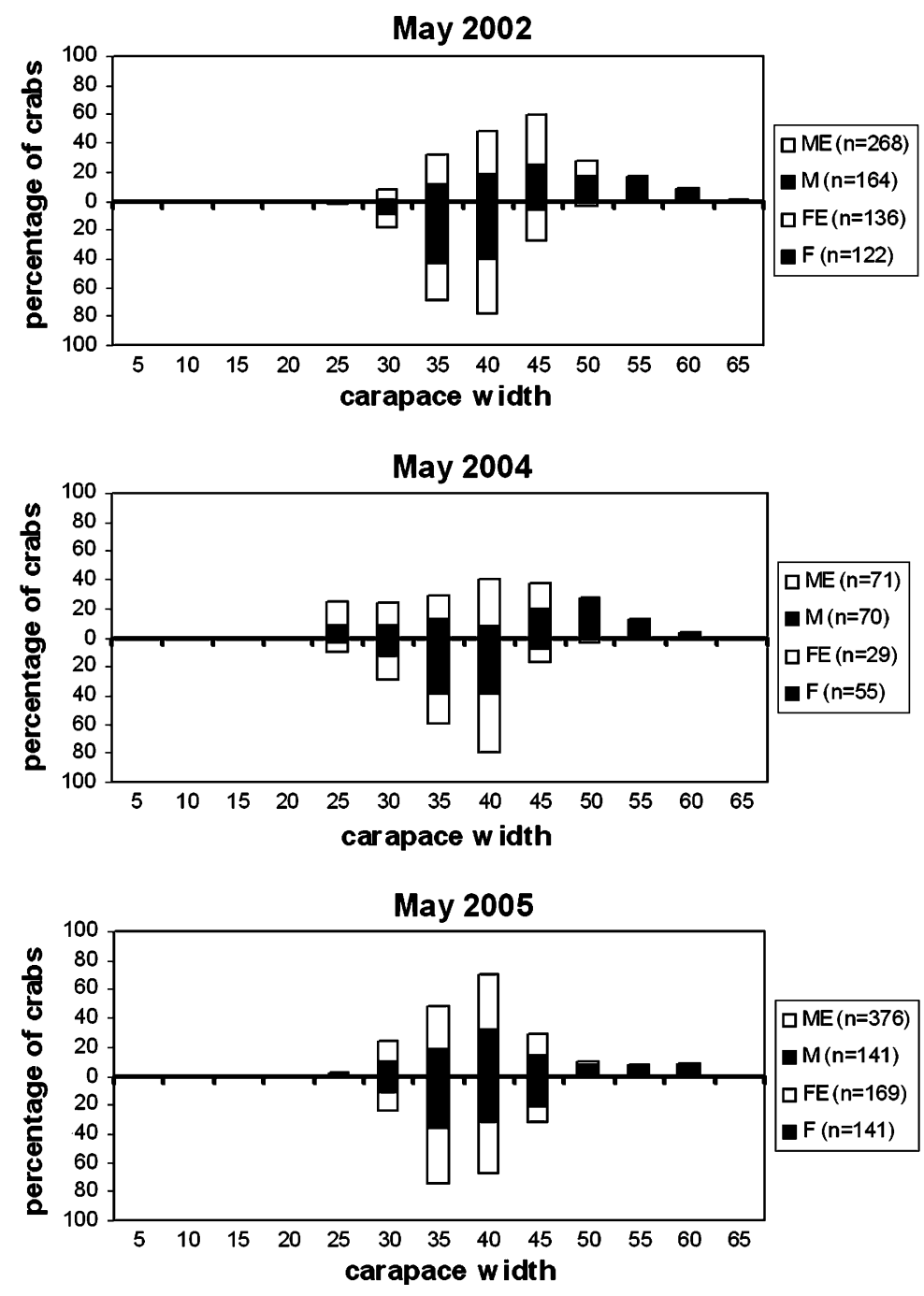

Fig. 3 Size frequency distribution of Charybdis longicollis in 2002, 2004 and 2005. M and F: uninfected males and females, $\mathrm{ME}$ and FE: externa-bearing males and females

Table 4 Number of Heterosaccus dollfusi externae per host in Palmahim

\begin{tabular}{|c|c|c|c|c|c|c|}
\hline & \multicolumn{2}{|c|}{ May 2002} & \multicolumn{2}{|c|}{ May 2004} & \multicolumn{2}{|c|}{ May 2005} \\
\hline & Total & $\%$ & Total & $\%$ & Total & $\%$ \\
\hline Uninfected & 286 & 46.3 & 125 & 66.8 & 282 & 39.1 \\
\hline 1 ext. & 174 & 28.2 & 39 & 20.9 & 184 & 25.5 \\
\hline 2 ext. & 114 & 18.4 & 17 & 9.1 & 124 & 17.2 \\
\hline 3 ext. & 35 & 5.7 & 4 & 2.1 & 72 & 10.0 \\
\hline 4 ext. & 9 & 1.5 & 1 & 0.5 & 40 & 5.5 \\
\hline$>4$ ext. & 0 & 0.0 & 1 & 0.5 & 19 & 2.6 \\
\hline Total & 618 & & 187 & & 721 & \\
\hline
\end{tabular}

parasite increased transmission efficiency. Though $H$. dollfusi has limited dispersal capabilities, it rapidly infected the Levantine populations, infecting within two years of its initial detection $62.6 \%$ of the Palmahim host population with 25-47 CW (Galil \& Lützen, 1995, Table 1), and $67.4 \%$ in June 1996 (Galil \& Innocenti, 1999). These values were similar to the prevalence of infestation in May 2002, 2004, and 2005. It was clearly established that heavily parasitized host populations bring about higher rates of multiple infestation: $48 \%$ of the externa-bearing hosts in 
the May 1994 sample bore more than one externa (Galil \& Lützen, 1995, Table 1), and $57.6 \%$ in June 1996 (Galil \& Innocenti, 1999), in line with the rate of multiple externae in May 2002 and 2005. The lower number of multiple externae bearing crabs in May 2004 was related to the dip in infestation that year.

Whereas males in the pre-infected population of C. longicollis were significantly larger than females (Galil \& Innocenti, 1999), the size gap diminished significantly in infected crabs. In post-infection populations the average and maximal size of uninfected males was increasingly reduced, though they were still larger than infected males. In female crabs, there was no difference between infected and uninfected specimens. Phillips and Cannon (1978) attributed the stunted host size to molt inhibition by the parasite, O'Brien and Van Wyk (1985) to fewer molts, Hawkes et al. (1987) to smaller molt increments. However, parasite-induced molt interruption fails to explain the size increase in parasitized female specimens. Since the fecundity of the parasite is related to externa size, and the latter is dependent on the size of the host (Galil \& Innocenti, 1999), it is proposed that $H$. dollfusi, capable of modifying its host morphology, physiology and behaviour, regulates the host size to best endure the significant metabolic costs of the reproductive externa, and provide it with optimal physical protection.

In its second decade in the Mediterranean, the population of $H$. dollfusi seems stable: despite the high prevalence of the parasite and its injurious impact on the host reproduction, the Erythrean invasive host-parasite pair reached a modus vivendi with no noticeable reduction in the host population, and continuing high rates of prevalence of infestation and multiple infestation. It is suggested that the high fecundity of the females, the "size refuge" formed by parasite-free larger males, and the "open" recruitment dynamics of C. longicollis, keep its population density high enough for $H$. dollfusi, with its "closed" recruitment dynamics, to maintain its pandemic infection rates. This 'natural experiment' acted out along the Levantine coast demonstrates that a parasitic rhizocephalan barnacle did not reduce the abundance of an invasive decapod host with widely dispersed planktonic larvae despite high infection rates. It is proposed these results bear important implications for attempts to utilize rhizocephalan barnacles for biological control of invasive decapods.

Acknowledgements We wish to thank Mel Cooper for his assistance in assembling the Israeli material, and Baki Yokes, for information on the Charybdis-Heterosaccus populations off SE Turkey. Stefano Cannicci provided assistance with statistical analysis. This manuscript was much improved by the comments of Catherine deRivera, Mark Torchin and an anonymous reviewer.

\section{References}

Boschma, H., 1960. A rhizocephalan parasite of the crab Charybdis hoplites (Wood-Mason). Crustaceana 1: 58-67.

Galil, B. S., 1986. Red Sea decapods along the Mediterranean coast of Israel: ecology and distribution. In Dubinsky Z. \& Y. Steinberger (eds), Environmental Quality and Ecosystem Stability, Ramat Gan, BarIlan University Press, IIIA/B:179-183.

Galil, B. S., 2000. A sea under siege-alien species in the Mediterranean. Biological Invasions 2: 177-186.

Galil, B. S., 2004. Exotic species in the Mediterranean Sea and pathways of invasion. In Proceedings of a seminar on The Effects of Human Transport on Ecosystems, Royal Irish Academy, 1-14.

Galil, B. S. \& J. Lützen, 1995. Biological observations on Heterosaccus dollfusi Boschma (Cirripedia: Rhizocephala), a parasite of Charybdis longicollis Leene (Decapoda: Brachyura), a lessepsian migrant to the Mediterranean. Journal of Crustacean Biology 15: 659-670.

Galil, B. S. \& G. Innocenti, 1999. Notes on the population structure of the portunid crab Charybdis longicollis Leene, parasitized by the rhizocephalan Heterosaccus dollfusi Boschma, off the Mediterranean coast of Israel. Bulletin of Marine Science 64: 451-463.

Hawkes, C. R., T. R. Meyers \& T. C. Shirley, 1987. Growth of Alaskan blue king crabs, Paralithodes platypus (Brandt), parasitized by the rhizocephalan Briarosaccus callosus Boschma. Crustaceana 52: 78-84.

Hines, A. H., F. Alvarez \& S. A. Reed, 1997. Introduced and native populations of a marine parasitic castrator: variation in prevalence of the rhizocephalan Loxothylacus panopaei in xanthid crabs. Bulletin of Marine Science 61: 197-214.

Høeg, J. T. \& J. Lützen, 1995. Life cycle and reproduction in the Cirripedia Rhizocephala. Oceanography and Marine Ecology: An Annual Review. 33: 427-485.

Innocenti, G., M. Vannini \& B. S. Galil, 1998. Notes on the behaviour of the portunid crab Charybdis longicollis Leene parasitized by the rhizocephalan Heterosaccus 
dollfusi Boschma. Journal of Natural History 32: 1577-1585.

Innocenti, G., N. Pinter \& B. S. Galil, 2003. Observations on the agonistic behavior of the swimming crab Charybdis longicollis Leene infected by the rhizocephalan barnacle Heterosaccus dollfusi Boschma. Canadian Journal of Zoology 81: 173-176.

Kuris, A. M., 1974. Trophic interactions: similarity of parasitic castrators to parasitoids. Quarterly Review of Biology 49: 129-148.

Kuris, A. M., 1997. Conceptual framework for biocontrol of introduced marine pests. In Proceedings of the First International Workshop on the Demography, Impacts and Management of Introduced Populations of the European Crab, Carcinus maenas, Center for Research on Introduced Marine Pests. Technical Report 11: 66-68.

Leene, J. E., 1938. The Decapoda Brachyura of the Siboga-Expedition. VII. Brachygnatha: Portunidae. Siboga Expeditie 39c3: 1-156.

Lewinsohn, Ch. \& L. B. Holthuis, 1964. New records of Decapod Crustacea from the Mediterranean coast of Israel and the Eastern Mediterranean. Zoologische Mededelingen, Leiden 40: 45-63.

O'Brien, J. \& P. Van Wyk, 1985. Effects of crustacean parasitic castrators (epicaridean isopods and rhizocephalan barnacles) on the growth of their crustacean hosts. Crustacean Issues 3: 191-218.
Øksnebjerg, B., R. Enzenross \& L. Enzenross, 1997. First record of Rhizocephala (Crustacea: cirripedia) from Turkish waters, with notes on Lessepsian migration. Stuttgarter Beiträge zur Naturkunde (Biologie) 557: $1-7$.

Ozcan, T., T. Katagan \& A. Kocatas, 2005. Brachyuran crabs from Iskenderun Bay (Southeastern Turkey). Crustaceana 78: 237-243.

Phillips, W. J. \& L. R. G. Cannon, 1978. Ecological observations on the commercial sand crab, Portunus pelagicus (L.), and its parasite, Sacculina granifera Boschma, 1973 (Cirripedia: Rhizocephala). Journal of Fish Diseases 1: 137-149.

Thresher, R. E., M. Werner, J. T. Høeg, I. Svane, H. Glenner, N. E. Murphy \& C. Wittwer, 2000. Developing the options for managing marine pests: specificity trials on the parasitic castrator, Sacculina carcini, against the European crab, Carcinus maenas, and related species. Journal of Experimental Marine Biology and Ecology 254: 37-51.

Torchin, M. E., K. D. Lafferty, A. P. Dobson, J. McKenzie \& A. M. Kuris, 2003. Introduced species and their missing parasites. Nature 421: 628-630.

Wolfe, L. M., 2002. Why alien invaders succeed: support for the Escape-from-Enemy Hypothesis. The American Naturalist 160: 705-711. 